
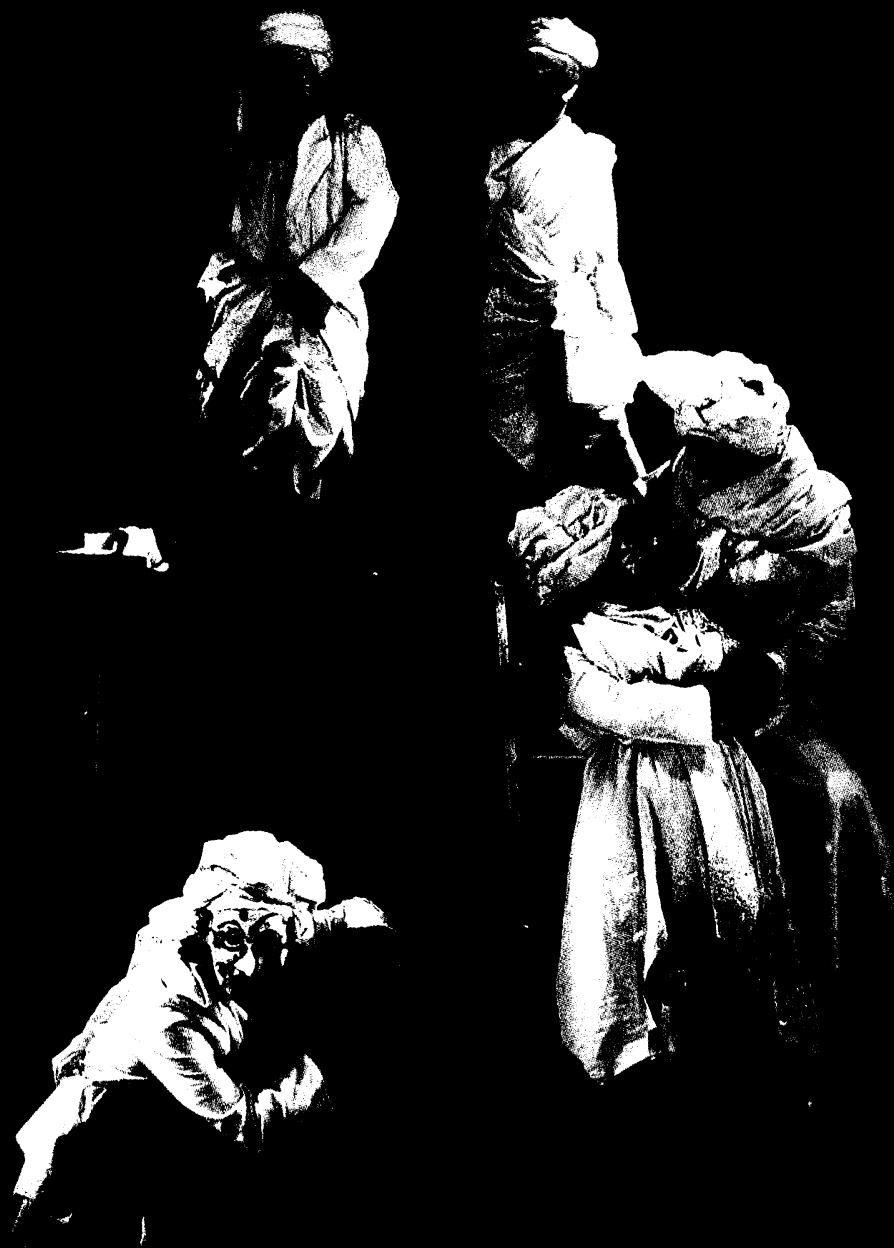


\section{Festival Iberoamericano de Teatro de Cádiz 2005: Lugar de encuentro de dos continentes}

\section{Miguel Ángel Giella}

El Festival Iberoamericano de Teatro (FIT) de Cádiz cumplió 20 años. Para celebrarlo, los organizadores decidieron invitar a algunos de los grupos y obras que estuvieron presentes en otras ediciones como Madame Curie de Nidia Téllez (1996) o El Quijote de Teatro de la Candelaria (1999), como así también a aquellos que habían asistido en años anteriores y que en esta ocasión presentaron nuevos montajes, y a otros que por primera vez se acercaron a los escenarios gaditanos con sus propuestas teatrales. En total, 32 espectáculos y más de 50 representaciones - aunque por razones técnicas el montaje de Carles Santos, El compositor, la cantante, el cocinero y la pecadora, se tuvo que cancelar - procedentes de Argentina, Bolivia, Brasil, Chile, Colombia, Costa Rica, Cuba, Ecuador, Estados Unidos, España y Uruguay, se llegaron hasta Cádiz del 18 al 29 de octubre - doce días frente a los diez habituales - con el fin de dar a conocer los diferentes lenguajes escénicos que tienen su origen a ambos lados del Atlántico.

\section{Dos Lorca}

La Cuadra de Sevilla (España), la compañía andaluza que más escenarios internacionales ha visitado en sus 34 años de existencia, fue la encargada de abrir esta vigésima edición del FIT de Cádiz con Yerma, Mater, bajo la dirección de Salvador Távora. Inspirada en la Yerma de Federico García Lorca, la obra fusiona música, baile, flamenco y poesía. La propuesta no deja de ser arriesgada ya que se trata de una peculiar versión - Yerma acaba dando a luz una hija de nombre Libertad simbolizada en la paloma blanca de la paz-de una de las obras más emblemáticas del autor granadino. Con una inmensa media luna ubicada al fondo del escenario comienza este montaje en el que se presenta una Yerma escindida en dos: por un lado, una 
actriz que recita un texto de forma pausada que la convierte en el eco de la conciencia, y lo hace desde lo alto de un toro hidráulico apresada en una camisa de fuerza, mientras que, por otro, una bailaora utiliza el baile como expresión del sentimiento trágico. Acompañan a la actriz y a la bailaora, una cantaora, unos músicos, un bailaor (el marido de Yerma) y un cantaor (el pastor, como posible encarnación de la fertilidad). Si bien la obra muestra la frustración e impotencia de una mujer que no puede llegar a tener hijos por razones sociales y religiosas, el conflicto trasciende para convertirse en la reivindicación de la libertad total de la mujer. La prensa criticó algunos cuadros que consideró extravagantes - como, hacia el final, una lluvia de palomas muertas esparcidas por el escenario - a la vez que señaló una tendencia al exceso y al barroquismo. Sin embargo, nadie puede negar la fuerza y contundencia de este espectáculo que intenta actualizar a García Lorca desde una mirada marcadamente provocadora.

El Centro Andaluz de Teatro presentó Llanto por Ignacio Sánchez Mejía, de Federico García Lorca, con dramaturgia y dirección de Concha Távora y el asesoramiento especial de Salvador Távora. La plaza de toros es el espacio elegido donde se desarrolla la adaptación del poema en el que García Lorca llora la muerte de uno de sus mejores amigos y toreros de la época. La puesta conjuga la música instrumental del oratorio de Maurice Ohana, el poema lorquiano, el cante flamenco y las raíces taurinas. El resultado es un drama de fuerte contenido simbólico cuyo texto se ve empañado por la declamación un tanto ampulosa de la célebre elegía del poeta de Fuente Vaqueros. Según se indica en el programa de mano, este Llanto... es también un homenaje a todos aquellos toreros casi anónimos que, como Sánchez Mejía, cayeron bajo las astas de otros toros en el ruedo o en siniestras enfermerías.

\section{Cervantes y El Quijote}

Teatro Avante (Estados Unidos), La Candelaria (Colombia), Pia Fraus (Brasil), Malayerba (Ecuador), La Compañía Nacional de Teatro Clásico (España), El Mirón Cubano (Cuba) y Guirigay Teatro (España) - estos dos últimos como espectáculos de calle - se sumaron con sus propuestas a los actos conmemorativos del cuarto centenario de la publicación de la primera parte de El Quijote.

El Teatro Avante de Miami presentó El vuelo del Quijote de Raquel Carrió y Lilliam Vega, bajo la dirección de esta última. El comienzo de la obra sitúa a Alonso Quijano en su lecho de muerte del que parece resucitar. 


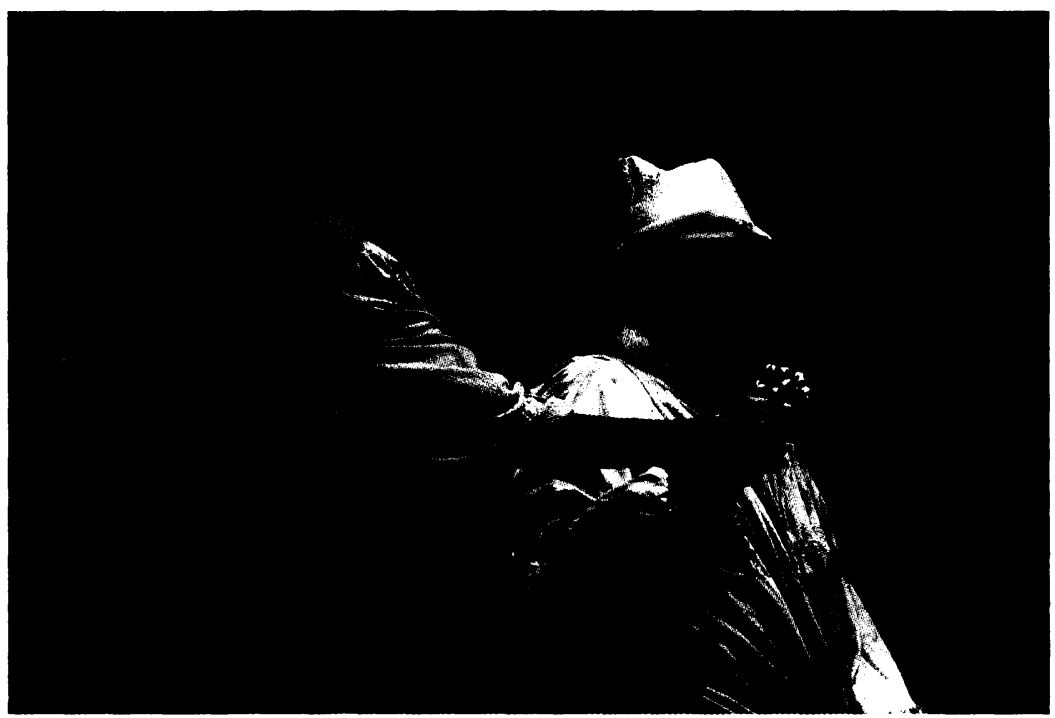

El vuelo de Quijote

Foto de Manuel Fernández

Su ama se torna Sancho y el clérigo se transforma en distintos personajes de la novela. De esta manera se inicia el viaje, la aventura, la capacidad de ilusión para poder volar, para que la imaginación vuele. Y así, ama y cura se creen los personajes de sus aventuras y terminan entrando en el juego del Caballero de la Triste Figura. Destaca por su actuación y por una magnífica voz Jacqueline Briceño en el papel de Ama / Sancho.

El Teatro La Candelaria puso en escena El Quijote, versión y dirección de Santiago García. La pieza, presentada en el FIT de 1999, desarrolla una serie de episodios - 12 cuadros caracterizados cada uno por un incidente - de la novela cervantina. La propuesta teatral, según su director, está sustentada en la acción como conflicto u oposición de fuerzas antagónicas en una serie de aventuras extraídas de la novela de Cervantes con la que se organiza una estructura en la que se rescata el espíritu festivo e irónico del texto clásico. La crítica periodística consideró que la puesta devaluaba el libro original por carecer el personaje del Quijote de la grandeza que lo caracteriza y estar acompañado de un Sancho desprovisto de sentido común. No obstante, y debido tal vez a que la obra tiene mucho de lúdico y carnavalesco, el público disfrutó del montaje y aplaudió a sus intérpretes.

Farsa Quixotesca, de la compañía Pia Fraus, fue otra de las adaptaciones del Quijote realizadas por uno de los grupos invitados a Cádiz. 
El espacio escénico consta de un telón de fondo transparente y opaco, que cambia según la iluminación, detrás del cual tienen lugar algunas de las acciones de esta puesta. Durante su desarrollo nos encontramos con caballos de alambre, dragones, inmensos libros y una Dulcinea que narra la historia de Alonso Quijano. Lo curioso de este montaje es que cuenta con tres quijotes y tres sanchos. En uno de los foros se le preguntó al autor del texto y director del espectáculo, Hugo Posolo, a qué se debía tal decisión, a lo que contestó que la razón era muy simple: había tres actores que querían hacer de Quijote. La música, los payasos y las marionetas están presentes en esta irreverente e ingeniosa propuesta brasileña.

La razón blindada, del grupo Malayerba, obra escrita, dirigida e interpretada - junto a Gerson Guerra - por Arístides Vargas, tal vez sea la versión más novedosa de las presentadas en esta edición del FIT, no sólo

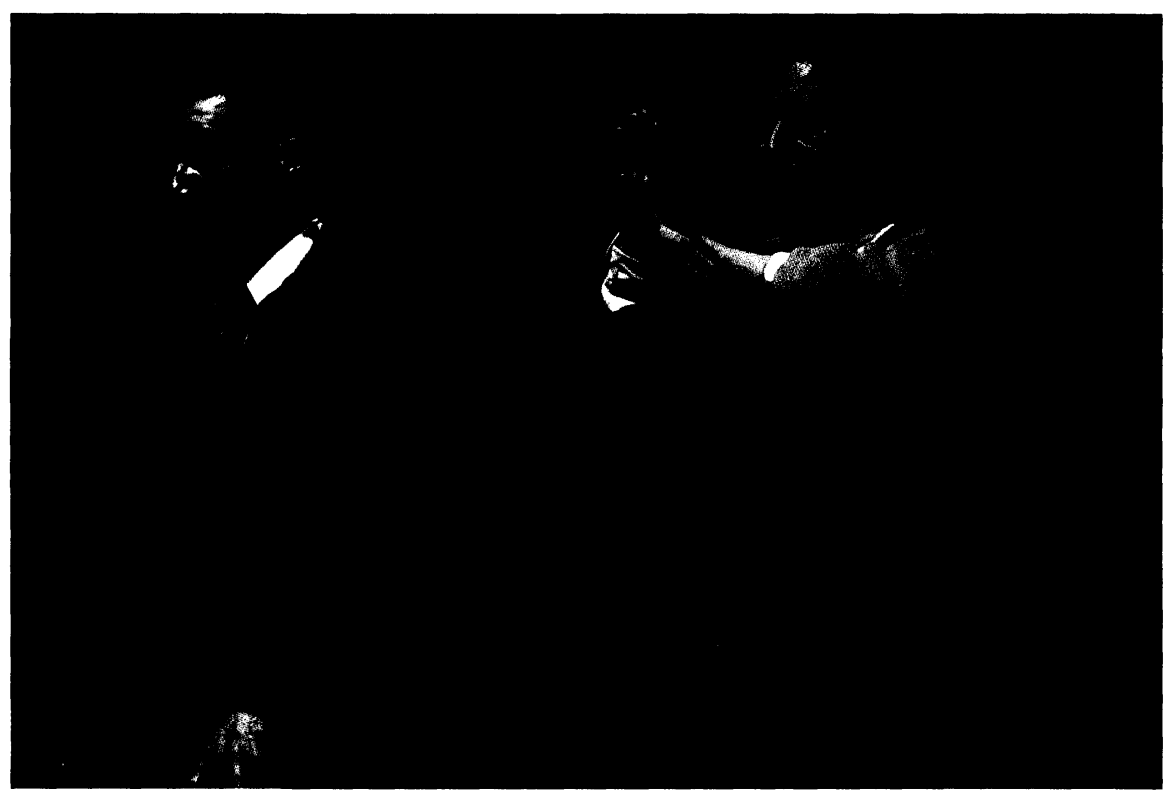

La razón blindada

Foto de Manuel Fernández

porque se inspira en El Quijote de Cervantes, en La verdadera historia de Sancho Panza de Kafka y en las narraciones que hicieron Chicho Vargas y otros presos políticos de la dictadura argentina de los años setenta en torno al penal Rawson, sino por la puesta en escena y el tipo de actuación elegidos que llevan el sello inconfundible de esta compañía ecuatoriana. Cámara negra. 
Dos presos se desplazan de un lugar a otro en sillas y mesas con ruedas. Mantienen encuentros culturales clandestinos para reinventar El Quijote, para contarse una historia que los salve, para que la imaginación los traslade adonde el dolor y la cruda realidad no puedan llegar. Como en otras obras de Vargas, el texto contiene una carga de humor necesaria que ayuda a soportar lo que allí se nos presenta. El ambiente opresivo que rodea a los personajes se percibe a través de la brillante interpretación de los dos actores que desarrollan una técnica teatral basada en una gran precisión de gestos, movimientos y desplazamientos.

La Compañía Nacional de Teatro Clásico escenificó El viaje al Parnaso, de Miguel de Cervantes en versión de Ignacio García May. Su director, Eduardo Vasco, nos indica en el programa de mano que han adaptado para la escena el poema, tratando de ofrecernos, a través de la teatralidad implícita en la obra cervantina y mediante procedimientos utilizados en escenarios de entonces y de ahora, su particular tributo al "dilecto manco en este año de celebraciones quijotescas." La música en directo (percusión, viola de gamba, arpa y corneta) se suma a esta original puesta en la que cinco excelentes actores vestidos de época se sirven de decenas de títeres (que representan a Cervantes y a un gran número de escritores coetáneos) para contarnos con humor esta visión satírica que el autor del Quijote nos ofrece del mundo de las letras de su tiempo.

\section{Propuestas dramáticas contemporáneas}

A las dramaturgias más recientes mencionadas en los apartados anteriores se suman otras que estuvieron presentes en Cádiz para participar en esta XX edición del Festival.

Contracciones de Marta Betoldi, con dirección de Mario Pasik, se estrenó en Buenos Aires dentro del ciclo Teatroxlaidentidad auspiciado por las Abuelas de Plaza de Mayo y la Secretaría de Derechos Humanos de la ciudad. El espacio escénico lo componen dos hamacas desde las cuales dos mujeres embarazadas transmiten una existencia llena de vida y dolor. Si bien escénicamente las mujeres aparecen en el mismo plano, sus discursos ponen en evidencia que las dos se encuentran en tiempo y espacio distintos. A medida que avanza la acción ambas historias se unen ya que los diálogos revelan que se trata de una madre y de su hija nacida en un centro de detención clandestina durante la última dictadura argentina. Como indica Marta Betoldi - que también actúa en la obra junto con Nacha Córdoba - la pieza es un acto de resistencia desde la vida, basado en el profundo amor que puede 


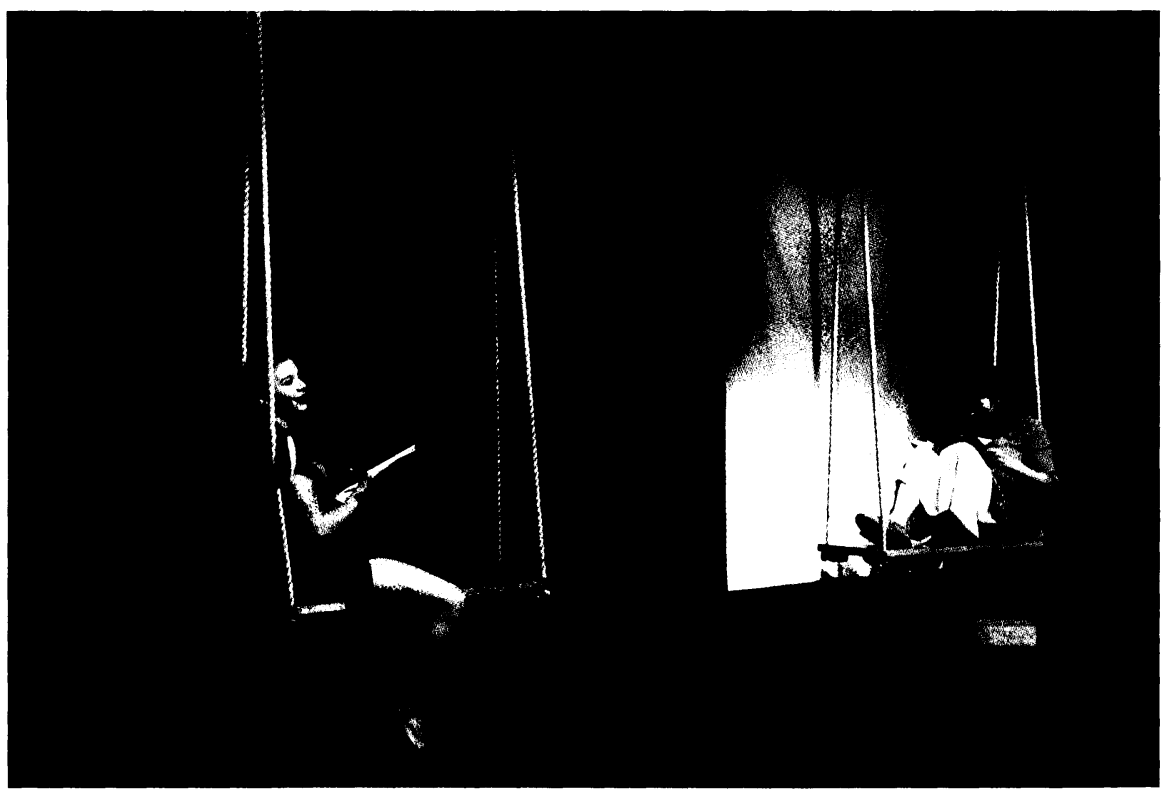

Contracciones

Foto de Manuel Fernández

transformar al mundo: el amor materno-filial; y es también un acto de resistencia desde el teatro como medio de expresión artística para poder movilizarnos y crear un ser mucho más "humano." El público aplaudió la interpretación de las actrices y el contenido del texto.

La Fronda (Argentina) presentó Ars higiénica, con dramaturgia y dirección de Ciro Zorzoli. La obra se basa en el Manual de urbanidad y buenas costumbres de Manuel Antonio Carreño, en el que se recogen una serie de formas y reglas sobre buenos modales para relacionarse en sociedad. En escena tres actrices y cinco actores, y dos armarios de madera con ruedas - con todo tipo de objetos en sus estantes - que entre todos se encargan de transportar de un lado a otro del escenario y con los que se van armando las sucesivas escenas. La acción es trepidante pues el grupo ejecuta constantes rutinas de higiene con el fin de ejercer un absoluto control sobre todo aquello que pueda resultar sucio, peligroso o que por tentador pueda arrastrarnos al caos. La actuación se fundamenta en movimientos y desplazamientos muy precisos. La pieza transmite la sensación de que todo está perfectamente reglamentado por un grupo de personas obsesionadas por el control y la higiene, $\mathrm{y}$, al mismo tiempo, pone en evidencia las nefastas consecuencias 
que este proceder ocasiona en una sociedad que es obligada a (sobre)vivir bajo normas muy estrictas.

El Teatro de los Andes (Bolivia) puso en escena Frágil, a partir de textos de César Brie y María Teresa Dal Pero, con fragmentos de Stefano Del Bianco, Paola Masino y Boris Viancon, y con dramaturgia y dirección de César Brie. La trama de Frágil comienza con una protagonista adulta (María Teresa Dal Pero en el papel de Lucía) que no entiende su lugar en el mundo. A través del desarrollo de la acción el público va descubriendo su pasado. Se la ve de niña con sus miedos y dudas y la presencia del abuelo, el único capaz de hablar su lenguaje. Luego se muestra como una adolescente que va planteando temas no siempre cómodos ni comprensibles para los adultos. El inicio de la pieza resultó ser uno de los mejores momentos de la representación - la muchacha arrastrando un corazón de gelatina y ataviada con un vestido blanco de papel - junto con el uso de un baúl en el que Lucía se resguarda de un mundo que no comprende y al que no quiere enfrentarse.

Antunes Filho y su compañía brasileña Macunaíma, fueron los encargados de escenificar una versión resumida (dura sólo 55 minutos) de la tragedia Antígona, de Sóflocles. El espacio escénico es una necrópolis subterránea donde yacen los héroes de las tragedias griegas. El montaje

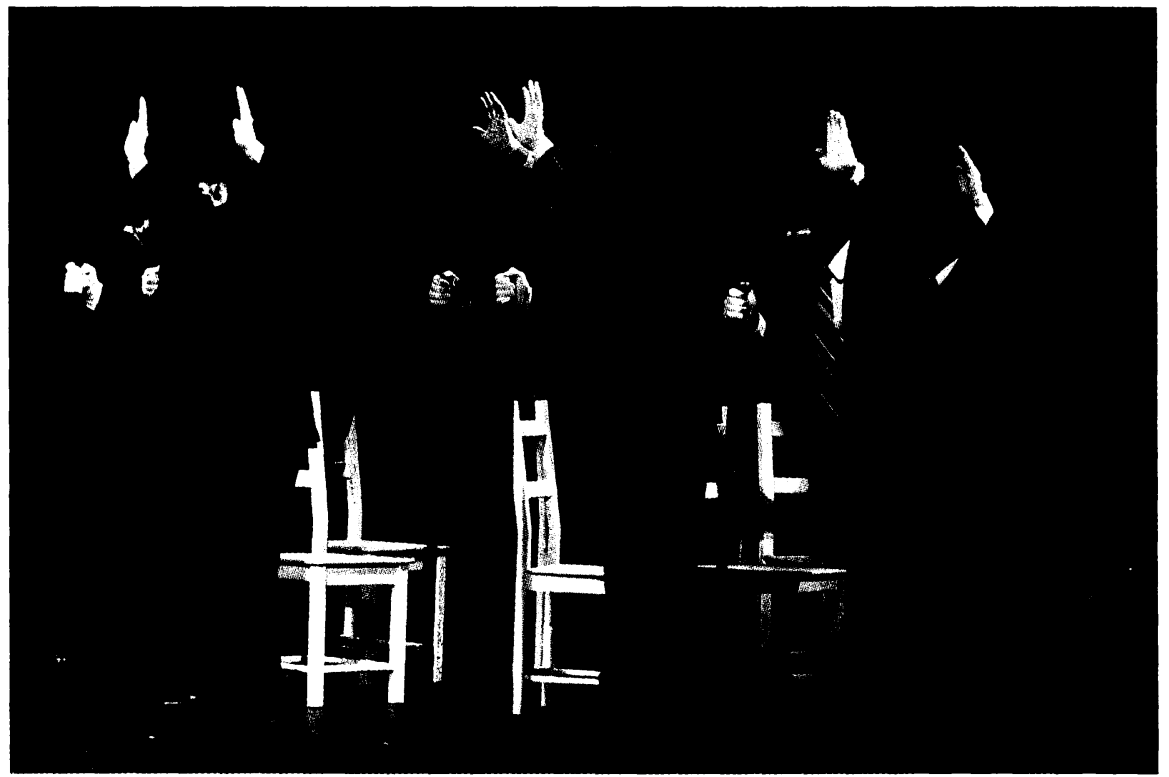


introduce al dios Baco, vestido con un traje de etiqueta blanco - una especie de maestro de ceremonias que sirve de nexo entre el mundo de los vivos y el de los muertos - quien ordena que saquen de sus tumbas a Antígona, Ismene y Creonte, para obligarlos a representar su historia una vez más. Durante el desarrollo se establece un contrapunto entre un coro de ancianos (cuya vestimenta consiste en traje y sombrero negros, máscara y guantes blancos y un bastón con el que golpean el suelo de forma rítmica para apoyar sus parlamentos) y un coro de bacantes fúnebres que entran y salen de escena, que se expresan modulando el grito y exhibiendo por momentos sus cuerpos desnudos. Hacia el final, resulta impactante la entrada en escena de Antígona, cubierta de pies a cabeza con un manto blanco y maniatada, en una silla de ruedas, como símbolo de su destrucción física y moral. Acertada interpretación brasileña de la tragedia de Sófocles que pone al descubierto el problema de la intolerancia.

Conjugado, un proyecto de Christiane Jatahy y Malu Galli de Vértice Teatro, con dramaturgia y dirección de Christiane Jatahy, fue otro de los espectáculos que llegaron de Brasil al FIT. Desde las gradas, unas 40 personas observan un cuarto aséptico y blanco, rodeado de persianas también blancas, en el que se encuentra una cama, un sillón, una mesa de luz, un cuarto de baño pequeño con una ducha, una nevera, un televisor y una pecera sobre un mueble. La protagonista enciende la luz, se desviste, se ducha, se pone una toalla sujetándole el pelo, hace gárgaras, habla con el pez (al que le da de comer), se vuelve a vestir, come chocolatinas (cuyos envoltorios guarda en un cajón), bebe coca-cola, apaga la luz y se sienta en el sillón a ver las noticias de la televisión. A los pocos segundos, enciende la luz y repite la misma rutina, una y otra vez. Finalmente, sale del cuarto y conduce al público hasta otros cuartos donde se pueden ver grabaciones reales de mujeres brasileñas que cuentan su propia versión de la soledad. El montaje dura unos 45 minutos. A la salida, la protagonista se encuentra fuera ya del espacio escénico junto a tres mujeres vestidas igual que ella. Lo que nos viene a decir que lo allí visto existe también entre nosotros. Tanto la actriz, Malu Galli, como el espectáculo, ya habían sido objeto de varios reconocimientos Premio Shell de Teatro 2004, mejor actriz y mejor escenografía; Premio Qualidade Brasil, mejor actriz y mejor espectáculo; mejor espectáculo de 2004 por la crítica de Río de Janeiro - con los que la crítica gaditana coincidió ya que resaltó el trabajo de la protagonista y consideró el espectáculo como uno de los preferidos de este FIT. 
Matadero Palma Teatro (Chile) presentó Lear (antes del mar), adaptación del Rey Lear de Shakespeare, para la que se utilizaron materiales de Juan Radrigán, Ray Loriga, Andrés Kalawski y Eugène Ionesco, con dirección de Francisco Albornoz. Según se indica en el programa de mano, se trata de un proyecto que indaga en temáticas como la relación padre-hija, la honestidad y la ambición, todos aspectos del espíritu shakesperiano pero no visto desde la óptica de clásico académico con la que suele aparecer en los escenarios, sino en una revisión actualizada y contingente. En esta versión, quedan sólo tres de los personajes principales: Lear, su hija Cordelia y el Bufón. Pensamos que si bien la propuesta es interesante y logra por momentos conectar con el público, en términos generales se nos presenta un rey Lear muy difícil de reconocer.

La Zaranda, Teatro Inestable de Andalucía La Baja, que a pesar del subtítulo cuenta con más de 25 años de andadura y es uno de los grupos más ligados al FIT, puso en escena bajo la dirección de Paco de la Zaranda, Homenaje a los malditos de Eusebio Calonge. El espacio escénico reproduce el ambiente de uno de esos cafés de tertulias literarias con mesas de mármol y sillas negras que trasmiten cierta decadencia y tenebrosidad. Hasta allí llega un grupo de poetas que han decidido homenajear a uno de sus pares al

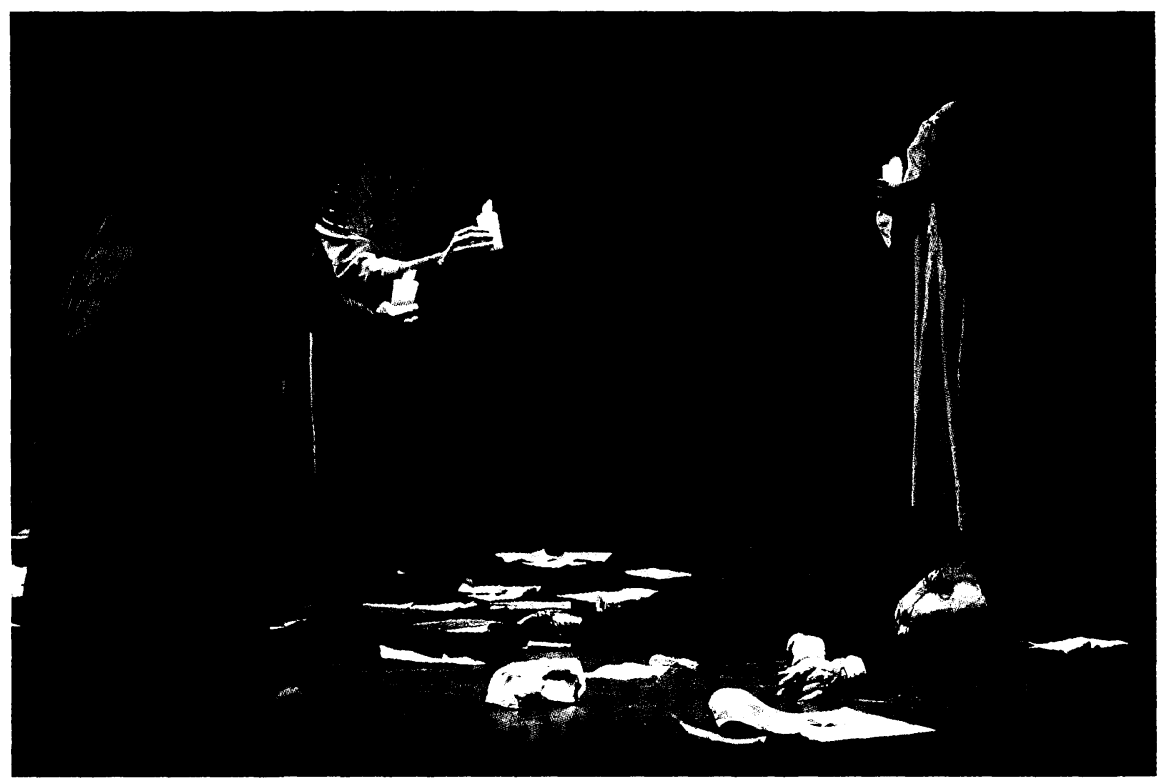


que llaman Maestro. Estos personajes sombríos, patéticos, fantasmagóricos muestran su peculiar visión sobre la condición humana. La obra rinde homenaje a los fracasados, a los perdedores, a todos aquellos que no tuvieron voz o a los que nadie se dignó escuchar. Y lo expresa de forma poética, con excelentes actores y actrices, con una austera escenografía, con una iluminación que consigue pasajes de una gran belleza plástica, y que sitúan a este espectáculo entre los mejores de este Festival.

El único estreno absoluto del FIT en esta edición fue español y se tituló Esperando a Diana, de Pedro Gómez y Eduardo Galán, con dirección de Celso Cleto. La trama se centra en un tema de rigurosa actualidad como es el de las parejas homosexuales y su posibilidad de adoptar niños. La obra intenta indagar en el concepto de familia que, indudablemente, ha variado en los últimos tiempos, y en cierta resistencia por parte de un sector de la sociedad a aceptar esos cambios. El material es dramatizable, todo depende de cómo se trate. Una parte de la crítica periodística gaditana consideró la pieza "como una comedia inteligente, por arriba de la media, armada con profesionalidad y recursos. Pero de ahí no pasa" (La Voz de Cádiz); mientras que otra parte vio en ella una obra comercial, ya que tiene, según el periodista, "todos los estilemas de las obras de su género. Una trama con un punto oportunista" por el tema que trata, con "un conservadurismo de fondo a pesar del aparente progresismo de la propuesta" (Diario de Cádiz).

De difícil clasificación es el bello montaje de Hermanos Oligor (España), cuya obra Las tribulaciones de Virginia se realiza dentro de una carpa con gradas en las que caben un número limitado de personas. La acción transcurre casi en la oscuridad - tal vez debería decir en la intimidad para ser más preciso - en un espacio circular con una pequeña pista en la que se puede vislumbrar todo tipo de objetos. La historia en sí es muy sencilla: Virginia, una muchacha que quiere ser bailarina, un día conoce a Valentín y los dos se enamoran. El montaje está hecho con muñecos, autómatas animados por poleas y pedales, juguetes mecánicos y máquinas inspiradas en experimentos de causa-efecto. Y detrás de todo ello está la presencia del actor, de su voz, de sus movimientos, con los que da vida a Virginia y Valentín, para crear un espectáculo realmente fascinante.

El Teatro Circular de Montevideo, que el año pasado celebró el cincuenta aniversario de su creación, es otro de los grupos emblemáticos de este Festival. En esta oportunidad el elenco uruguayo llevó a escena Onetti en el espejo, de María Esther Gilio, en versión escénica de Hiber Conteris, con dirección de Patricia Yosi. El texto del montaje está sacado de las 


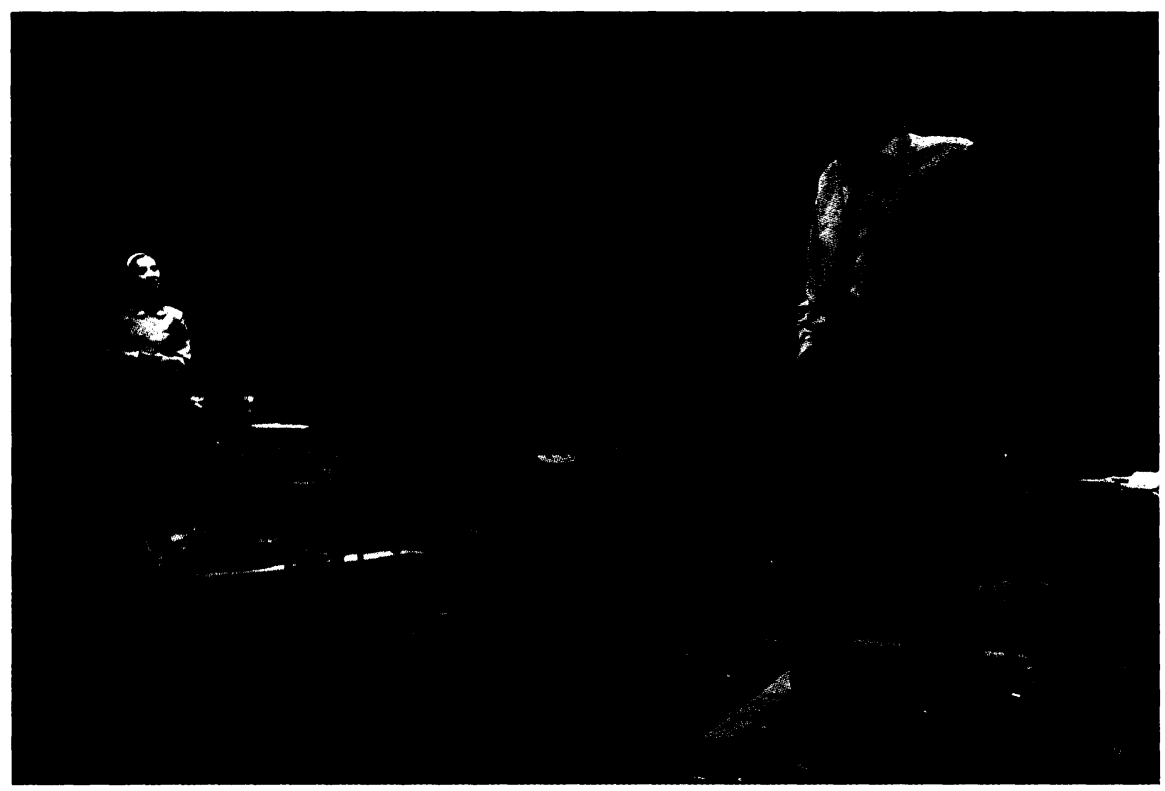

entrevistas que la periodista María Esther Gilio le hizo al escritor Juan Carlos Onetti entre 1965 y 1993. A través de los encuentros en Montevideo, Buenos Aires y Madrid podemos ver cómo evoluciona la relación entre estos dos personajes - desde la primera entrevista en la que se produce un cierto enfrentamiento hasta las últimas en las que se observa una gran amistad - y, al mismo tiempo, ser testigos de unos agudos careos dialécticos, no exentos de humor, que ambos sostienen en el desarrollo de la acción dramática. De las respuestas del escritor a las acertadas preguntas de la periodista se puede entrever sus preocupaciones y avatares, su angustia existencial, sus gustos, sus obsesiones, como así también algunos de los secretos de su creación literaria. Magnífica actuación de Walter Reyno y Paola Venditto, protagonistas de este canto a la amistad entre una periodista y uno de los narradores contemporáneos más importantes en lengua castellana.

Con el mismo vestuario que la acompañó en su primera actuación y las mismas claves escénicas, Nidia Telles regresó al FIT con la obra que triunfó en 1998, Madame Curie, de Mira Michalowska, dirigida por Jorge Curi. La actriz, que es también la traductora del texto, recrea en un espacio íntimo y en constante interacción con el público, la vida y obra de Madame Curie a través del testimonio de una periodista americana, Mary Mattingley 
Melony, que la entrevistó en 1920 y que luego se convirtió en la mayor promotora de la obra de esta científica en Estados Unidos. Nidia Telles interpreta a las dos mujeres mientras recorre varias salas en compañía del público asistente. La crítica gaditana, siete años después, volvió a ensalzar el trabajo actoral de esta estupenda actriz uruguaya.

Els Comediants (España) fueron los encargados de clausurar esta edición del FIT en el Gran Teatro Falla con Las mil y una noches, adaptación y dramaturgia de Joan Font y Luisa Hurtado, con dirección del propio Font. El espacio escénico está formado por una estructura metálica de tubos que llegan casi hasta el techo, que ocupa gran parte del escenario y que representa las ruinas de la Biblioteca Nacional de Bagdad tras el incendio del edificio durante la invasión de Irak, y en el que se quemaron más de un millón de libros. Un grupo de personas está abocada a la tarea de rescatar los libros que quedan. Una especialista en literatura antigua (aunque en realidad es el espíritu de Sherezhade) encuentra el de Las mil y una noches, momento en el cual comienza a relatar algunos de los cuentos. Acompañados de música en directo, los actores se sirven de las técnicas del clown, del mimo y la comedia del arte para dar vida a las historias fantásticas que se narran en este clásico de la literatura árabe.

\section{Espectáculos de danza y calle}

Diquis-Tiquis (Costa Rica) estuvo en Cádiz por primera vez en 1991; volvió en 1992, y en aquella ocasión estrenó el espectáculo que trajo este

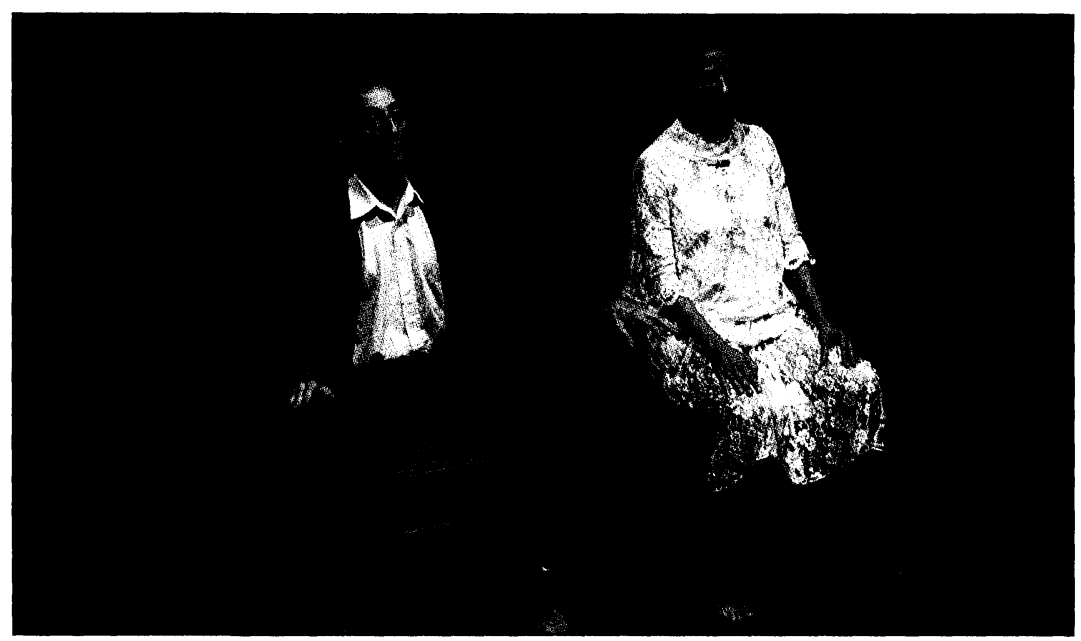


año, Paredes de brillo tímido, con los mismos intérpretes (Sandra Trejos y Alejandro Tosatti) y las mismas coreografías - de Adriana Castaños (México), Oscar Naters (Perú), Sandra Trejos y Alejandro Tosatti. Esta pareja de actores-bailarines utilizan un lenguaje novedoso en el que se articulan de forma no muy común danza, teatro y mimo. El espacio escénico está formado por dos sillas sobre las cuales y a su alrededor ambos intérpretes desarrollan toda la función con movimientos muy precisos creando una sucesión de imágenes bellas e impactantes.

Gá-gá, creación y dirección de Marta Carrasco (España), fue otro de los espectáculos de danza que combina teatro y expresión corporal. Unos

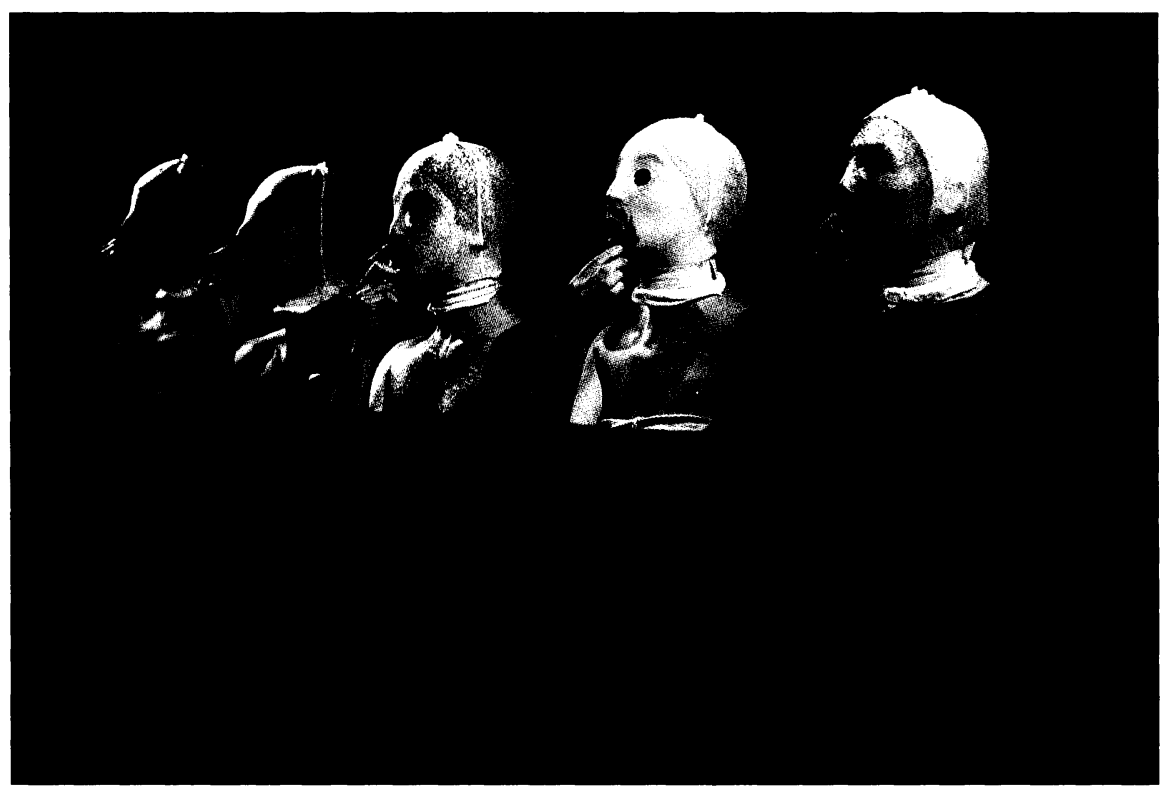

seres extraños con la cabeza cubierta con una especie de media blanca y con el torso al aire surgen por detrás de la parrilla del telar - que se encuentra a ras del escenario - desde donde cuelgan los focos y telones. Intentan montar su propio espectáculo pero, por más que ensayan, fracasan una y otra vez. El espectáculo explora la risa como alimento, como oxígeno para poder vivir, y lo hace a través de esta delirante e ingeniosa propuesta para disfrute y diversión del público asistente. 
Réquiem 21 K626 de José María Roca, dirigido por Gema López, y Bloque C, Ángeles caídos buscan subir al cielo, con dirección y coreografía de Alicia Soto, fueron las dos propuestas españolas de danza en la calle. La primera, de Producciones Imperdibles, es parte de una serie sobre "Las miradas de la danza." El espectador observa desde una estructura metálica con dos niveles de altura, las terribles e impactantes imágenes de guerra, campos de concentración o actos terroristas que se proyectan sobre un suelo blanco mientras los intérpretes bailan al ritmo del Réquiem de Mozart. La segunda, de la compañía Hojarasca Danza, combina baile y acrobacia, y muestra a tres seres que llegan vestidos de obreros a construir un andamio; una vez acabada la estructura comienza la transformación en ángeles que, eventualmente, se convertirán en mujeres.

Entre los espectáculos de calle figuran dos grupos de Argentina: Dúo Tangorditos, con MAGorditos que nunca, en el que la magia, el clown, el circo, el tango y la improvisación están presentes; y El Gran Maximiliano que, en El mundo de las ilusiones, presenta números de magia con uno en particular de escapismo inspirado en Houdini; Pia Fraus muestra en Bishos do Brasil la gran riqueza de la fauna brasileña por medio de tres intérpretes que bailan, manipulan muñecos hechos de calabazas e imitan los movimientos de los animales, en un alegato a la conservación de la naturaleza ejecutado con humor y efectividad; El Mirón Cubano presentó De la extraña y anacrónica aventura de don Quijote en una insula del Caribe y otros sucesos dignos de saberse y representarse, en la que don Quijote y Sancho sueñan un viaje marítimo que los lleva hasta una isla del Caribe gobernada por un burro, y que da lugar al hidalgo manchego a realizar otra de sus temerarias hazañas. Hubo varias propuestas españolas: Pandora, de Artristrás Teatre, es un espectáculo donde doce actores y bailarines dan vida a todos los personajes y monstruos gigantescos surgidos de la mítica y enigmática caja; ...En el laberinto, de Guirigai Teatro (farsa quijotesca inspirada en el texto cervantino) narra las andanzas de cuatro caballeros de distintos lugares y procedencias, que acompañados de tres músicos con instrumentos de viento y percusión, ataviados con máscaras y haciendo uso de alguna pirotecnia, recorrieron las calles gaditanas uniendo la plaza de San Antonio con la del Teatro Falla; Circo efimero es un espectáculo circense en el que una equilibrista (llamada la mujer araña), unos malabaristas, unos músicos y un maestro de ceremonias muestran, en un reducido espacio, su habilidad y destreza en la ejecución de los diferentes números. Xarxa Teatre fue el encargado de clausurar - con el mismo espectáculo que lo hiciera en 1992 - 
el FIT callejero con El foc del mar, original de Vicent Martí Xar. En la Plaza de la Catedral tuvo lugar este montaje lleno de imágenes espectaculares basado en las fallas de Valencia y en la estética de Miró.

\section{Actos complementarios}

Dentro de los actos programados se realizó el IX Encuentro de Mujeres de Iberoamérica en las Artes Escénicas, que tuvo como tema "Espacios de Representación." Hubo tres exposiciones: "Trajes y tipos en El Quijote. Fondos de Indumentaria del Museo Nacional del Teatro," "CELCIT: 30 años de historia," y "FIT de Cádiz: La ventana de América (20 años del Festival Iberoamericano de Cádiz)." Esta última se complementó con la edición de un libro-catálogo que lleva el mismo título que la exposición, coordinado por Désirée Ortega Cerpa, y que se presentó dentro de un acto presidido por la alcaldesa de Cádiz Teófila Martínez y el actual director del FIT José Bablé, en el que se homenajeó a los dos anteriores directores Juan Margallo y José Sanchis Sinisterra, al director del Centro Latinoamericano de Creación e Investigación Teatral (CELCIT) Luis Molina y al primer director técnico del Festival José Luis Alonso. El actor argentino Héctor Alterio recibió el VI Premio Atahualpa del Cioppo en el Salón de Plenos del Ayuntamiento

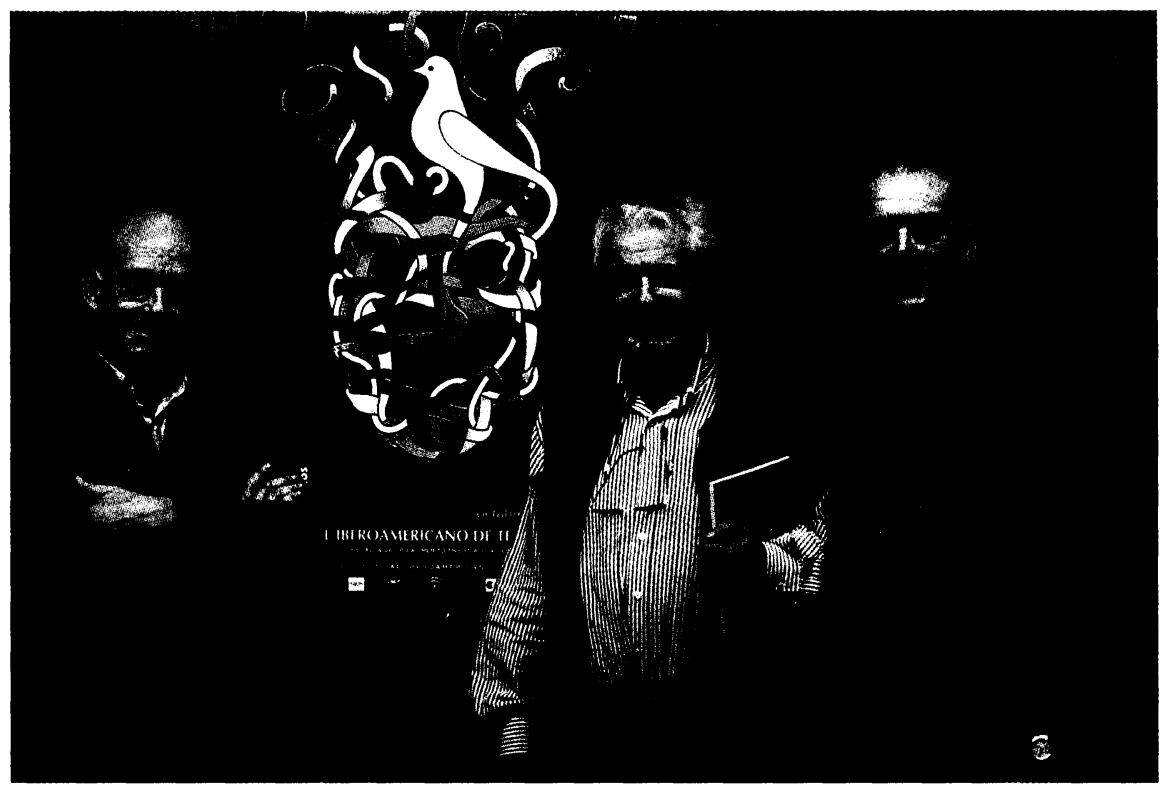

José Sanchis Sinisterra, Juan Margallo y José Bablé 


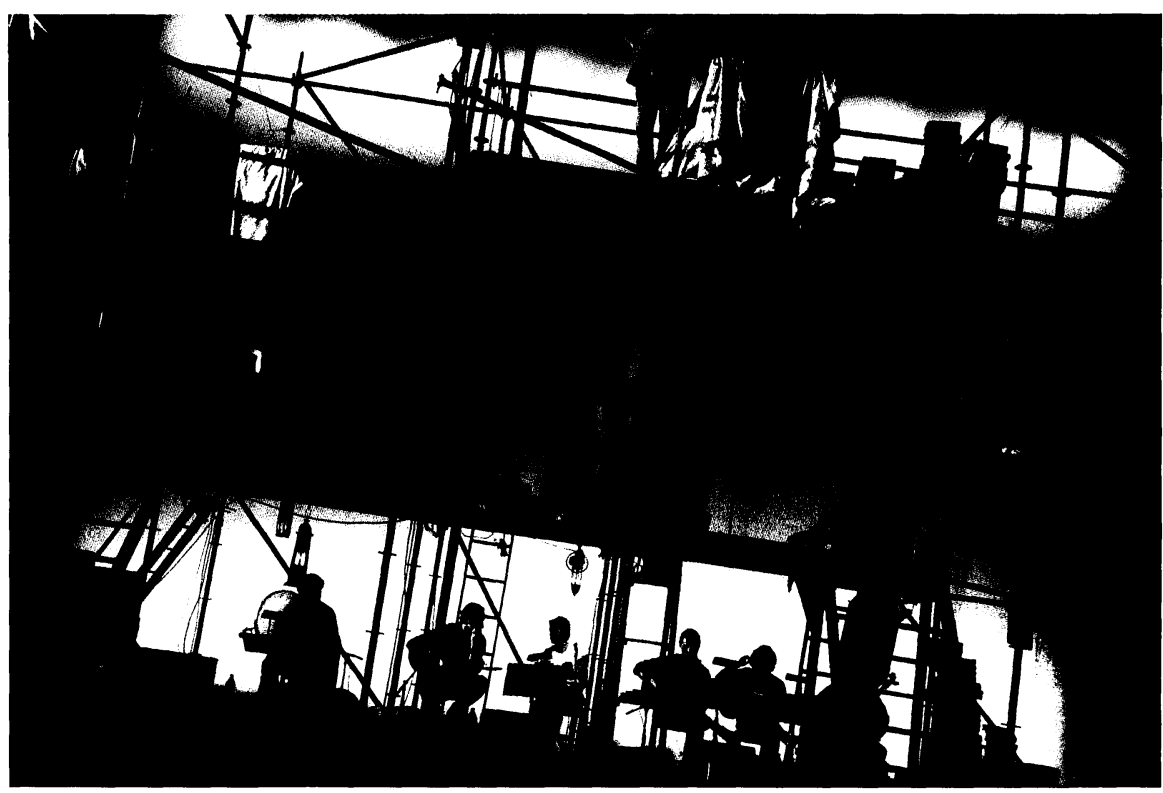

Els Comediants Las mil y una noches

de Cádiz en reconocimiento a su carrera profesional. En el mismo Salón de Plenos se iba a llevar a cabo un homenaje a Norma Aleandro, pero se tuvo que suspender debido al fallecimiento de la madre de la actriz en Buenos Aires. Las Jornadas Internacionales de Solidaridad con el CELCIT, en su 30 aniversario, se centraron en la recuperación del Teatro de la Veleta en Almagro. El 15 de julio de 2005 un incendio arrasó este punto de operaciones de la escena iberoamericana, acabando con la memoria - atrezzos, documentos, libros, vídeos - de muchos años de trabajo. Luis Molina comentó que más de 80 grupos se habían ofrecido para ayudar al CELCIT con actuaciones benéficas para reunir fondos con vistas a la reconstrucción del teatro. Como en años anteriores, hubo una presentación de libros y revistas de teatro. Finalmente, coordinados por Eberto García Abreu, se celebraron los foros críticos. En esta ocasión, se propuso un temario central que contó con la intervención de los grupos participantes, críticos e investigadores teatrales, en el que se intercambiaron ideas y vivencias sobre la escena iberoamericana actual.

FIT de Cádiz 1986-2005: veinte años de teatro latinoamericano y español. Felicidades. 